Published in final edited form as:

J Public Health Dent. 2017 March ; 77(2): 136-147. doi:10.1111/jphd.12187.

\title{
The Black Dentist Workforce in the United States
}

\author{
Elizabeth Mertz, PhD, MA [Associate Professor], \\ UCSF School of Dentistry \\ Jean Calvo, \\ UCSF Dental Student Class of 2017 \\ Cynthia Wides, MA [Research Analyst], and \\ UCSF School of Dentistry \\ Paul Gates, DDS, MBA [Chairman] \\ Bronx-Lebanon Hospital Center Dental Department
}

\section{Abstract}

Objectives-The purpose of this paper is to describe the Black dentist workforce, the practice patterns of providers, and their contributions to oral health care for minority and underserved patients.

Methods-A national sample survey of underrepresented minority dentists was conducted in 2012 and received a 32.6\% response rate for self-reported Black dentists. Data were weighted for selection and response bias to be nationally representative. Descriptive and multivariable statistics were computed to provide a workforce profile of Black dentists. National comparisons are provided from published data.

Results-Among all Black dentists (weighted $n=6,254$ ), 76.6\% self-identify as AfricanAmerican, $13.2 \%$ as African, and $10.3 \%$ as Afro-Caribbean. The largest share of Black dentists are male, married, heterosexual, born in the U.S. and raised in a medium to large city. One third of Black dentists were the first in their family to graduate from college. Black dentists report higher average educational debt than all dental students, graduates from International Dentist Programs having the greatest debt. Traditional practices (i.e., private practices) dominate, with $67.1 \%$ of Black dentists starting out in this setting and $73.5 \%$ currently in the setting. Black dentists care for a disproportionate share of Black patients, with an average patient mix that is $44.9 \%$ Black. Two in five Black dentists reported their patient pool is made up of more than $50 \%$ Black patients.

Conclusions-The underrepresentation for Black dentists is extraordinary, and the Black dentists that are in practice are shouldering a disproportionate share of dental care for minority and underserved communities.

\section{Keywords}

Dentist's Practice Patterns; African Americans; Survey Research; Health Workforce 


\section{INTRODUCTION}

Blacks, Hispanic/Latinos and American Indian/Alaska Natives have a disproportionally lower presence in the dental workforce compared to the United States (U.S.) population overall and are cumulatively referred to as underrepresented minorities (URM)(1). The Surgeon General and Institute of Medicine have recommended that remediation of this imbalance of URM dentists would be an important avenue to improve cultural competency among dentists, decrease health disparities among patients, and increase access to care and improve health outcomes in underserved populations (2-4). The theory that minority patients are more likely to seek care from a provider of similar race or ethnicity and experience improved health outcomes as a result is known as racial concordance. Several studies have demonstrated improved health access and outcomes for patients receiving health care from racially concordant providers (5-10).

The Black population in the U.S. has documented disparities in oral health (2). Black adults are twice as likely to have unmet dental needs when compared to Whites and face many barriers to accessing dental care $(11,12)$. Black children are nearly twice as likely to have suboptimal oral health status and have fewer routine preventive dental visits compared with White children (13). Nationwide initiatives have sought to improve cultural competency and increase the number of minority providers in the U.S., but Black dentists are still greatly underrepresented within the dental workforce $(14,15)$. Little is known about the practice patterns of Black dentists. A 1992 survey of 772 Black dentists by Drs. Paul Gates and Sheila Price in conjunction with West Virginia University collected data on the Black dental workforce, but results were never published (16), and limited practice details in 1996 by race from a small sample was conducted and limited to professionally active dentists (1). The aim of this paper is to describe the Black dental workforce, the practice patterns of Black providers, and to provide a preliminary examination of their contribution to oral health care for Black and other underserved patients.

\section{METHODS}

Data for this study comes from a national sample survey of URM dentists completed in 2012-2013 under IRB-approved study number 11-07905 at the University of California, San Francisco (17). The American Dental Association (ADA) masterfile used to select the sample contained 12,983 URM dentists practicing in the U.S. in 2012, of which 6,585 were identified as Black. The final sample included 2,434 Black dentists and was based on RuralUrban Commuting Area codes, with a census of 140 rural dentists and 531 suburban dentists, and a sample of 1,763 urban dentists. A detailed description of methodology for the survey sampling and response has been previously published. (17) A total of 368 (15.1\%) dentists were removed from the sample as ineligible, and a total of 673 eligible responses were received for a response rate of $32.6 \%$ (Table 1). Resource limitations did not allow for a larger sample of Black dentists nor a control group of non-URM dentists.

The survey instrument allowed respondents to select more than one category of racial and ethnic identity and also allowed for Black dentists to further self-identify as AfricanAmerican, African or Afro-Caribbean. Supplementary Table 1c online provides details on 
the racial/ethnic composition of Black dentists. For each respondent who identified as more than one of our study populations [American Indian/Alaska Native (AI/AN), Black, and Hispanic/Latino (H/L)], we assigned a primary race for analytic purposes based on several variables including self-identified race/ethnicity, location raised, organized dentistry affiliations, languages spoken, tribal affiliations or blood quantum, and work history. This yielded eight dentists moving from their original sampling frame of either AI/AN or $\mathrm{H} / \mathrm{L}$ to Black, and another 16 dentists from the Black sampling frame to either AI/AN or H/L. This resulted in a weighted total of 6,254 Black dentists in the U.S., 331 fewer than were identified in the original ADA masterfile. All data are weighted using base and poststratification weights to adjust for selection likelihood and correctible, measureable response bias. Non-correctable response bias, survey methodology, response rate, and response quality have been previously reported and we believe the data set is nationally representative of the Black U.S. dentist workforce (17). U.S. Census population data was linked to the survey data through the provider's mailing address to allow for analysis of provider and population distribution (18). Univariate and multivariable descriptive statistics were computed on the weighted Black dentists' survey responses.

\section{RESULTS}

\section{Black Dentists' Demographic Characteristics}

Among all Black dentists in the U.S., 76.6\% self-identify as African-American $(n=4,791)$, $13.2 \%$ as African $(\mathrm{n}=822)$, and $10.3 \%$ as Afro-Caribbean $(\mathrm{n}=641)$. The majority of Black dentists are male (54.6\%), married or in a civil union/domestic partnership (68.0\%), heterosexual (98.8\%), born in the U.S. (84.6\%), and raised in a medium to large city (69.3\%). African and Afro-Caribbean Black dentists are more likely to have been born outside of the U.S. (44.1\% and 80.1\%, respectively) than African-American Black dentists (2.1\%). Foreign-born Black dentists are slightly younger, with $48.8 \%$ being under age 45 compared to $32.2 \%$ of U.S.-born Black dentists. Detailed demographic characteristics of all URM dentists are provided in Supplementary Table 2 online.

Approximately one-third of Black dentists were the first in their family to graduate from college. The parents of dentists under age 49 were more likely to have attended college or graduate school -- $72.1 \%$ for fathers and $74.9 \%$ for mothers -- than were older dentists' parents, $49.2 \%$ and $47.2 \%$, respectively. Black dentists' parents are typically educated at the same levels as one another, with the exception that the mothers of dentists age 49 or older were less likely to have attended or completed graduate school than the fathers. These data indicate that younger Black dentists come from more highly and equally educated parents than in the past. Detailed parental education tables for all URM dentists are provided in Supplementary Tables 3 and 4 online.

\section{Black Dentists' Education, Licensure, and Professional Membership}

Three pathways to practice were discernable among Black dentists: 1. Initial degree at a Commission on Dental Accreditation (CODA)-accredited dental school (U.S.-trained), 2. Foreign-trained initially followed by graduation from a CODA-accredited school (International Dentist Program, or IDP), and 3. Foreign-trained. Any pathway can be 
augmented with residency. Almost all Black dentists are U.S.-trained, with approximately $1 \%$ taking the IDP pathway and foreign-trained pathways, respectively (Table 2). African dentists comprised $68.1 \%$ of ever foreign-trained Black dentists (pathways $2 \& 3$ ), and dentists born outside the U.S. were more likely to be foreign-trained than those born in the U.S.

Among U.S.-trained Black dentists, $58.1 \%(\mathrm{n}=3,511)$ attended a private dental school, as did $89.1 \%(\mathrm{n}=57)$ of IDP-trained Black dentists. Among all Black dentists who attended a private dental school, $75 \%(\mathrm{n}=2,685)$ attended a historically Black college or university (HBCU); 58\% at Howard University College of Dentistry and $42 \%$ at Meharry Medical College School of Dentistry (19). The majority (51\%) of Black dentists age 49 or older attended an HBCU dental school, while 34.9\% attended a public dental school. Among Black dentists under age 49 , the inverse is true: $50.2 \%$ attended a public dental school and $35.1 \%$ attended an HBCU dental school (Table 3). Hence, a shift has occurred in the educational location of Black dentists, not just away from HBCUs, but towards public dental schools.

After completing dental school, 33.3\% ( $\mathrm{n}=2,040)$ of Black dentists completed a general dentistry residency [Advanced Education in General Dentistry (AEGD)/General Practice Residency (GPR)], 11.1\% ( $\mathrm{n}=681)$ completed a specialty residency, and $6.4 \%(\mathrm{n}=393)$ completed both. Almost half $(49.2 \%, \mathrm{n}=3,015)$ did not complete a residency program, which is relatively consistent across age groups.

The average educational debt at graduation varied greatly by the dentists' pathways to practice. In 2012 dollars, the average debt reported by Black dentists in our survey was $\$ 147,994$, and only $8.5 \%$ of Black dentists reported graduating without debt. Foreign-trained Black dentists who completed a residency reported either having no debt at graduation $(62.4 \%, \mathrm{n}=33)$ or having finished paying off their debt $(37.6 \%, \mathrm{n}=20)$, and their average debt was the lowest, reported at $\$ 23,891$. U.S.-trained Black dental graduates' average debt was $\$ 148,397$, while IDP-trained Black graduates reported the highest average debt at $\$ 204,509$.

The American Dental Education Association (ADEA) reports that between 1996-2010 the average of the annual average educational debt of all students in 2012 dollars was $\$ 147,871$ for all schools, $\$ 122,200$ for public schools, and $\$ 183,578$ for private schools (20). In this same timeframe (1996-2010), Black dentists in our survey reported an average total debt of $\$ 167,792$. Average debt (2012 dollars) in the 1996-2010 timeframe varies by educational setting, at $\$ 195,418$ for non-HBCU private schools, $\$ 175,783$ for HBCU, and $\$ 141,747$ for public schools.

To examine the impact of educational debt on practice decisions, respondents were able to select all that applied among 11 options. Among all Black dentists, $46.4 \%(n=2,823)$ indicated that their education debt did not impact their practice choice after graduation; however, among foreign-trained Black dentists $82.5 \%$ reported debt had no impact. Among U.S.-trained dentists, the most frequently selected impact of educational debt was not being able to afford to start a practice (21.9\%) or to buy a practice (17.1\%), or accepting a position as an associate $(20.9 \%)$ or as an employee $(17.7 \%)$. 
The majority of Black dentists ( $74.5 \%, \mathrm{n}=4,565)$ hold an active license in only one state. Almost half $(46.1 \%, \mathrm{n}=2,882)$ of Black dentists reported membership in the ADA, and $35.3 \%(\mathrm{n}=2,211)$ reported membership in the National Dental Association (NDA). Approximately $35 \%(\mathrm{n}=774)$ of Black dentists reported a membership in both the ADA and the NDA, while $27.0 \%(n=1,675)$ reported having no membership in a professional association. African-American dentists were more likely to be members of the NDA (37.4\%, $\mathrm{n}=1,792)$ than were African $(28.1 \%, \mathrm{n}=231)$ or Afro-Caribbean dentists $(29.2 \%, \mathrm{n}=187)$.

\section{Black Dentists' Career Trajectory}

Among all Black dentists, $98.5 \%(\mathrm{n}=6,158)$ reported being professionally active and of these, $91.6 \%(\mathrm{n}=5,641)$ are clinically active. Just $1.5 \%(\mathrm{n}=96)$ reported not working in the dental field. Reasons reported for not working were retirement $(35.0 \%, \mathrm{n}=34)$ and disability $(\mathrm{n}=37.2 \%, \mathrm{n}=36)$. Of those not currently working, $29.1 \%$ indicated being highly likely to return to dental practice, while $30.7 \%$ were uncertain whether they would return to practice and $40.3 \%$ ( $n=37$ ) were unlikely or highly unlikely to return to practice.

All Black dentists, except those currently enrolled in a residency $(n=16)$, were asked to provide information on their initial employment location, and professionally active dentists were asked to provide information on their current primary and secondary practices. Table 4 classifies specific practice types and provides a breakdown of initial and current practice settings. Black women dentists are more likely than their male colleagues to be working in safety-net (13.8\% vs. $8.3 \%)$ and corporate (7.5\% vs. $2.9 \%)$ settings. African American Black dentists were less likely to report working in the safety-net setting (9.1\%) than AfroCaribbean (12.7\%) and African (13.5\%) Black dentists, but more likely to report working in public setting (6.8\% vs. $4.8 \%$ and $2.5 \%$ respectively).

We examined the career trajectories of professionally active Black dentists from their first practice as a dentist to their current primary practice (Table 5). Dentists who work in industry positions were excluded due to their small numbers. The largest share of Black dentists $(66.7 \%, \mathrm{n}=3,497)$ began their career as a dentist in traditional practice settings, and, over time, $86.7 \%(\mathrm{n}=3,030)$ of those who started in a traditional setting remained. Black dentists who began their careers in safety-net or public settings were the least likely to remain in their initial setting (29.5\% and $28.5 \%$, respectively). Movement into traditional practice from another setting was highest for Black dentists who started in safety-net settings (51.5\%), followed by public settings (47.3\%), corporate (36.6\%), and education (33.9\%). Those who began their careers in corporate (92.1\%) and public settings (91.2\%) had the highest rates of having participated in a Community Based Experience (CBE) "often" or "sometimes" during dental school.

Three quarters of professionally active Black dentists $(76.3 \%, \mathrm{n}=4,425)$ reported that their primary area of practice is general dentistry, and across both general and specialty practice areas, $26.5 \%(n=1,550)$ report being board certified in their primary practice area.

Additional areas of clinical focus were reported by 2,904 providers and include: cosmetic dentistry (62.3\%), implantology (47.1\%), orthodontics (25.4\%), geriatrics (14.2\%), anesthesia (13.2\%), special care (12.5\%), and hospital dentistry (7.3\%). Among the 5,913 
Black dentists who indicated how long they are likely to keep working, the majority (58.0\%, $\mathrm{n}=3,430$ ) intend to practice for an additional 10 years or longer.

\section{Black Dentists in Clinical Practice}

Among clinically active Black dentists, 56.5\% $(n=3,471)$ reported owning their own dental practice. The majority of owners built their own practice $(66.1 \%, \mathrm{n}=2,295)$, while $25.5 \%$ $(\mathrm{n}=884)$ purchased an existing practice as a sole owner, and 6.3\% $(\mathrm{n}=219)$ purchased an existing practice as a partner. The average Black dentist's clinical setting has two dentists, two registered dental hygienists, and 6 operatories.

Sixty-nine percent $(n=3,906)$ of clinical Black dentists reported whether they work with expanded function dental assistants, hygienists, or therapists. Of these, $68.7 \%(n=2,683)$ are practicing in a state that allows employment of expanded function staff. Among Black dentists in allowing states, $55.9 \%$ work with these staff and $44.1 \%$ do not. Those in corporate $(74.5 \%)$, public $(68.0 \%)$, and safety-net $(65.6 \%)$ settings were most likely to work with expanded function staff.

Black dentists work on average 41.1 hours per week, spending an average of 31.2 hours in direct patient care. Black dentists reported treating an average of 59 scheduled and 9 walk-in patients per week but this varies by setting. Dentists in corporate settings reported treating the highest average number of scheduled patients per week (74), followed by those in traditional settings (62), public settings (54), and safety-net and education settings (fewer than 50).

When asked about their workload, 31.3\% ( $\mathrm{n}=1,645)$ of Black dentists reported not being busy enough while $44.2 \%(n=2369)$ reported being able to see all patients requesting appointments without being over worked. Yet, $82.4 \%(\mathrm{n}=3,180)$ of dentists in traditional settings said they were either "not busy enough" or "not overworked" compared to only $55.7 \%$ ( $\mathrm{n}=690$ ) of dentists in all other settings. Among Black dentists employed in safety-net practices, $47.7 \%(n=245)$ reported being over worked or too busy to see all patients requesting appointments compared to $17.6 \%(\mathrm{n}=679)$ of dentists in traditional settings.

The average income in 2011 of all Black dentists $(n=4,203)$ was reported to be $\$ 144,779$; those working in safety-net practices $(\$ 125,576)$, public health $(\$ 106,962)$, and education $(\$ 109,003)$ reported lower than average annual income while those in traditional $(\$ 152,601)$ and corporate $(\$ 159,225)$ practices reported higher than average incomes. The ADA reported in 2014 the net income of all dentists in private practice was $\$ 170,000$.(21) Female Black dentists reported an average income of $\$ 129,063$ compared to male Black dentists at $\$ 157,720$, and this gender gap was found across all age categories, with the largest gap $(\$ 76,956)$ in the $45-54$ age cohort.

\section{Black Dentists' Patient Characteristics}

Fifty-three percent $(n=2,702)$ of Black clinically active dentists reported that they primarily treat underserved patients at their primary practice, and an additional 5.5\% $(n=280)$ report having a secondary practice at which they primarily treat underserved patients. Dentists age 49 and older were more likely to treat primarily underserved patients $(64.1 \%, \mathrm{n}=1,824)$ 
compared to their younger colleagues $(35.9 \%, \mathrm{n}=1,022)$. Tables 6 and 7 describe the patient population reported by Black clinically active dentists.

Ninety-four percent $(n=4,764)$ of Black clinical dentists report treating patients with diabetes. The average percent of diabetic patients treated by all Black clinical dentists was $25.5 \%$, which is more than twice the U.S. population average $(9.1 \%)(22)$. The average percent of patients with developmental disabilities (5.8\%) was more than double that of the percent of the general population in the U.S. with developmental disabilities (2.5\%) (23). The average percent of patients with hypertension (34.5\%) is close to being on par with percent in the general U.S. population (32.5\%) (24).

Black clinical dentists reported the largest share of their patient population is Black, on average $44.9 \%$. Among clinical dentists, $27.6 \%(n=1,372)$ reported treating children under the age of $1,69.4 \%(n=3,455)$ reported treating children ages two to 5 , and $67.9 \%(n=3,381)$ reporting treating patients over 85 . African-American Black dentists reported slightly more black patients on average (45.5\%) than African (43.3\%) and Afro-Caribbean (42.1\%) Black dentists. Thirty percent $(n=1,317)$ of clinical Black dentists reported public insurance programs covered a majority of their patients. Comparatively, the ADA's Survey of Dental Practice from 2012 suggests that all private practice dentists reported an average of only $6.1 \%$ of their patients being publicly insured in 2012.(25) African Black dentists reported a mean percent of publicly insured patients (36.6\%) that was higher than the mean for African American (30.3\%) and Afro-Caribbean (28.5\%) Black dentists. Most Black dentists (69.2\%, $n=3,524)$ reported discounting or waiving fees for patients who are either uninsured or unable to pay for an average self-reported value of $\$ 53,952$. The patient profile of Black dentists indicates they are a critical access point for minority and low income populations to gain dental care.

\section{Professional Collaboration, Technology Use \& Volunteerism}

Dentists were asked the extent to which they collaborated with other dentists and seven types of other health care providers (e.g., doctors, nurses, pharmacists, etc.). Among Black clinically active dentists in safety-net settings, 58.5\% reported collaborating "often" or "sometimes" with four or more types of non-dental health care providers while among those in traditional settings, only $16.9 \%$ collaborated at this level.

Black clinical dentists were also asked to report use, or intent to use, among 15 different information technology tools in their dental practice. Three of these technologies are commonly used in the treatment of vulnerable populations: teledentistry, phone translation services, and mobile dental equipment. Only $7.7 \%(\mathrm{n}=392)$ of Black dentists had mobile equipment, $8.9 \%(\mathrm{n}=463)$ had teledentistry capacity and $21.5 \%$ had phone translation services. Dentists in education (42.3\%) and safety-net settings (30.3\%) were the most likely to utilize two or more of these technologies. Online Supplementary Tables 5 and 6 provide details on clinical collaboration and technology.

Dentists are often asked to volunteer their services, and among all Black dentists currently working in the dental field (including those working in non-clinical settings), 53.5\% $(n=3,346)$ reported volunteering any time as a dentist outside of their own office. Of dentists 
who volunteer, $49.1 \%(\mathrm{n}=1,643)$ do so less than 3 days a year, 37.6\% $(\mathrm{n}=1,259)$ reported volunteering between $3-11$ days per year, $11.3 \%(n=380)$ reported volunteering 1 day per month, and $1.9 \%(\mathrm{n}=65)$ reported volunteering two days per month or more in an average year. Half of Black dentists $(51.7 \%, \mathrm{n}=3,232)$ reported where they volunteer with the most common volunteer location being at organized community events $(74.1 \%, \mathrm{n}=2,394)$, such as health fairs or Remote Area Medical (RAM)-type events, followed by schools (28.0\%, $\mathrm{n}=907)$, a local community or tribal clinic $(16.3 \%, \mathrm{n}=528)$, locations outside of the U.S. $(11.2 \%, \mathrm{n}=360)$, and hospitals $(5.0 \%, \mathrm{n}=161)$. Among the reasons given for providing volunteer dental services, $92.3 \%(\mathrm{n}=2,988)$ of Black dentists indicated a "desire to give back." Comparative data on collaboration, technology use and volunteerism are not nationally available for all dentists.

\section{Geographic Distribution of Black Dentists in the U.S}

Dentists are not evenly distributed across the U.S., and the distribution of Black dentists varies from the distribution of all dentists. Supplementary Table 7 provides the distribution of all URM dentists by Census Division. Black dentists are more concentrated in the southeastern U.S. compared to the distribution of all dentists (26) (Figure 1). In fact, more than 1 in 3 Black dentists reside in the South Atlantic Division.

The distribution of Black dentists also varies in relation to the overall Black population in the U.S. (Figure 2). The smallest Black dentist to Black population ratio $(1: 5,516)$ is found in the Mountain Division, reflecting the small population of both Black dentists and the Black population in this Division (18) The greatest ratio, at 1:10,595, is in the West North Central. All regions exceed the ratio of 1:5,000, the level at which the Health Resources and Services Administration (HRSA) can consider an area to qualify as a Dental Health Professional Shortage Area, highlighting the extent of the workforce disparity (27).

\section{Comparison with 1992 Unpublished Black Dentists Data}

A survey of U.S. Black dentists was conducted in 1992 by Drs. Paul E. Gates and Sheila Price in conjunction with West Virginia University. The results of this survey were never published but the results were made available for comparison to this study. The survey was mailed to 3,237 Black dentists in the U.S. and yielded a $23.1 \%(n=748)$ return rate. The 1992 results are not weighted to be nationally representative and therefore cannot be considered directly comparable with our study data; however, when examining the results of both studies a few items are noteworthy (Table 8).

The 1992 survey results show fewer female and fewer single dentists and also reports dentists working 10 fewer hours each week. A higher proportion of respondents to the 1992 survey were working in general dentistry. Likewise, slightly more of the 1992 respondents had not completed a residency or specialty training. Dentists in 1992 reported higher participation rates in organized dentistry in organizations such as the ADA and NDA. Fewer Black dentists reported being sole proprietors, and more reported that their practice is "not busy enough" in 2012 compared to 1992. Close to one in five Black dentists in 1992 stated their first job in dentistry was in the armed forces, whereas 2012 data shows less than one in ten dentists serving in armed forces dentistry immediately after dental school. 
Some of the most notable differences between data collected in 1992 and this current study pertain to reported patient demographics. Compared with 1992 data, the current data indicates Black dentists now have more diverse patient pools. About half (47.5\%) of Black dentists in 1992 reported that $75 \%$ or more of their patients were Black; however, in 2012 only 1 in 5 Black dentists (20.4\%) reported this high proportion of Blacks in their patient pool. Furthermore, Black dentists whose patient populations are more than 25\% Hispanic have increased from $8.1 \%$ in 1992 to $30.7 \%$ in 2012.

\section{Study Limitations}

Data are based on a weighted sample of respondents from a response rate of $32.6 \%$. Item non-response is present, although minimal. Respondents were asked questions which require memory across a variety of years and so may be subject to recall bias. Comparisons can be made to national data sources, but we do not have non-URM comparison groups in our dataset from which we can conduct statistical tests of difference. How representative the unpublished 1992 survey data are is unknown. A full discussion of the survey methodology, response rate, weighting and adjustment for bias as well as limitations has been previously published (17).

\section{DISCUSSION}

This study provides the first comprehensive description of the Black dentist workforce in the U.S. with a focus on specific data relevant to caring for vulnerable and underserved populations. The Black dentist workforce is quite diverse and is changing over time. Broad brush comparisons across racial/ethnic groups do not capture this rich diversity within a population - a diversity that is critical if we are to truly understand the drivers behind the workforce trends that impact access to high quality, culturally competent care. For example, in our data we see that African and Afro-Caribbean dentists are younger and more likely to be female than Black dentists who identify as African-American. As well, from 1972 to 2012, foreign-born Black dentists increased at an average rate of $0.4 \%$ a year, and $5 \%$ of the Black workforce now self-identifies as multi-racial. Younger Black dentists come from more educated families, are twice as likely to be raised in the suburbs, and half as likely to be raised in rural communities as their older peers, while the older dentists are more likely to serve underserved patients. We cannot assume that the patterns of the past will predict the patterns of the future.

Black dentists take on greater educational debt, compared to the national average, to finance their educations. Yet, they also report treating a disproportionate share of minority patients that are minority and patients covered by public insurance. Black women dentists are more likely to work in safety-net settings and across all age spectrums as compared to Black male dentists, yet report significantly lower annual income, raising important questions about equity, practice location, and how to support providers in serving underserved populations.

Our practice pattern analysis clearly shows that although many individuals do not start in a traditional practice, the draw toward this model over time is strong, with three-quarters of providers currently in a traditional practice model. Only $17.5 \%$ of Black dentists go on to specialize compared to approximately $20 \%$ nationally (28), raising questions about what 
might be limiting further education and practice opportunities for minority providers. More than half of dentists who are located in states allowing expanded function staff report working with these staff, showing a willingness to adapt and expand the models of their practice. As the landscape of American dentistry changes over time, continuing to monitor the relationship between opportunity and intent will be important to ensure a healthy, diverse workforce as well as access to care for the U.S. population.

Even with the preponderance of Black dentists working in a traditional practice setting, the vast majority report serving underserved patients in their practices. They also serve a greater percentage of medically compromised patients than the U.S. average, with an emphasis on hypertension and diabetes. And importantly, Black dentists provide a disproportionate share of dental care for the Black population. While this pattern requires more investigation, it is irrefutable that Black dentists provide the bedrock of oral health care for the Black population. As the Affordable Care Act drives more individuals to having dental coverage and with the Medicaid population expanding (29), asking who will take care of the underserved is a critical question that remains unanswered.

Blacks make up $13.6 \%$ of the U.S. population but only $3.3 \%$ of U.S. dentists. The number of Black dentists would have to increase four-fold to reach population parity, a raw increase of 19,714 Black dentists. U.S. dental school enrollment data indicate that up to 1,779 Black dental students may graduate between 2012 and 2017 (30). Our study indicated that 1,111 Black dentists intended to retire during the same period, leading to an increase of 668 Black dentists in the six-year period, a net of almost 112 new Black dentists per year. While this is a step in the right direction for increasing dental workforce diversity, holding all else constant, it would take 176 years to close the gap to parity at this rate. Even though U.S. dental schools are expanding enrollment, the percent of Black students has remained steady, or perhaps even declined (31).

\section{CONCLUSION}

Among the number of strategies being discussed as solutions to address the unacceptably high burden of dental disease in the African-American population, improving the workforce diversity of dental providers is critical. The vast oral health disparities experienced by the Black population in the U.S. (4), beneficial outcomes of concordant healthcare relationships (8), the low numbers of Black dentists, and high prevalence of Black dentists caring for the underserved and minority populations demonstrated in our study demands that we do a better job of enhancing workforce diversity (17). The extent of the underrepresentation for Black dental providers is dauntingly high and those that are in practice are shouldering a disproportionate share of dental care for minority and underserved communities. This study profiles a diverse and changing Black dentist workforce, a profile that raises important questions about the dentist pipeline. Workforce diversity clearly can only be one of many broader strategies to address oral health equity and improve the disparities in minority oral health care. 


\section{Supplementary Material}

Refer to Web version on PubMed Central for supplementary material.

\section{References}

1. Brown LJ, Wagner KS, Johns B. Racial/ethnic variations of practicing dentists. J Am Dent Assoc. 2000; 131(12):1750-4. [PubMed: 11143740]

2. Institute of Medicine. Improving Access to Oral Health Care for Vulnerable and Underserved Populations. Washington, DC: National Academies Press; 2011 May.

3. Institute of Medicine. Advancing Oral Health In America. Washington, DC: National Academies Press; 2011 Apr.

4. U.S. Department of Health and Human Services. Oral Health in America: A Report of the Surgeon General. Rockville, MD: U.S. Department of Health and Human Services; 2000.

5. LaVeist TA, Nuru-Jeter A, Jones KE. The association of doctor-patient race concordance with health services utilization. J Public Health Pol. 2003; 24(3-4):312-23.

6. Malat J, van Ryn M, Purcell D. Blacks' and whites' attitudes toward race and nativity concordance with doctors. J Natl Med Assoc. 2009; 101(8):800-7. [PubMed: 19715044]

7. Meghani SH, Brooks JM, Gipson-Jones T, Waite R, Whitfield-Harris L, Deatrick JA. Patientprovider race-concordance: does it matter in improving minority patients' health outcomes? Ethnic Health. 2009; 14(1):107-30.

8. Schnittker J, Liang K. The promise and limits of racial/ethnic concordance in physician-patient interaction. J Health Polit Polic. 2006; 31(4):811-38.

9. Bender DJ. Patient preference for a racially or gender-concordant student dentist. J Dent Educ. 2007; 71(6):726-45. [PubMed: 17554091]

10. Health Resources and Services Administration. The Rationale for Diversity in the Health Professions: A Review of the Evidence. U.S. Department of Health and Human Services; 2006 Oct.

11. Mueller CD, Schur CL, Paramore LC. Access to dental care in the United States. J Am Dent Assoc. 1998; 129(4):429-37. [PubMed: 9573693]

12. Saha S, Arbelaez JJ, Cooper LA. Patient-physician relationships and racial disparities in the quality of health care. Am J Public Health. 2003; 93(10):1713-9. [PubMed: 14534227]

13. Flores G, Lin H. Trends in racial/ethnic disparities in medical and oral health, access to care, and use of services in US children: has anything changed over the years? Int J Equity Health. 2013; 12:10. [PubMed: 23339566]

14. Andersen RM, Friedman JA, Carreon DC, Bai J, Nakazono TT, Afifi A, et al. Recruitment and retention of underrepresented minority and low-income dental students: effects of the Pipeline program. J Dent Educ. 2009; 73(2 Suppl):S238-58. S375. [PubMed: 19237360]

15. Formicola AJ, D'Abreu KC, Tedesco LA. Underrepresented minority dental student recruitment and enrollment programs: an overview from the dental Pipeline program. J Dent Educ. 2010; 74(10 Suppl):S67-73. [PubMed: 20930230]

16. Gates, Paul. Personal Communication. 2014.

17. Mertz E, Wides C, Cooke A, Gates P. Tracking workforce diversity in dentistry: importance, methods and challenges. J Public Health Dent. 2016; 76(1):38-46. [PubMed: 26183241]

18. U.S. Census Bureau. 2010 Census Summary File 1, Tables QT-P3 and P6. In: generated by C. Wides using American FactFinder, editor. 2015.

19. Gates PE, Ganey JH, Brown MD. Building the minority faculty development pipeline. J Dent Educ. 2003; 67(9):1034-8. [PubMed: 14518843]

20. American Dental Education Association. ADEA Survey of Dental School Seniors, 2012 Graduating Class Tables Report. Washington, D.C: Mar. 2014

21. American Dental Association. Income, Gross Billings, and Expenses: Selected 2014 Results from the Survey of Dental Practice (Tables in Excel). Chicago, IL: Health Policy Institute; 2015 Dec. 
22. American Diabetes Association. Statistics About Diabetes. 2014. Available from: http:// www.diabetes.org/diabetes-basics/statistics/

23. Morstad, D. How Prevalent Are Intellectual and Developmental Disabilities in the United States?. Watertown, WI: Bethesda Institute; 2012.

24. Centers for Disease Control and Prevention. Hypertension. Washington, D.C: 2014. Available from: http://www.cdc.gov/nchs/fastats/hypertension.htm

25. American Dental Association. Characteristics of Private Dental Practices: Selected 2014 Results from the Survey of Dental Practice (Tables in Excel). Chicago, IL: Health Policy Institute; 2015 Dec.

26. U.S. Department of Health and Human Services, Health Resources and Services Administration, National Center for Health Workforce Analysis. National and State-Level Projections of Dentists and Dental Hygienists in the U.S., 2012-2025. Rockville, MD: 2015.

27. U.S. Department of Health and Human Services, Health Resources and Services Administration, National Health Service Corps. Health Professional Shortage Area (HPSAs) Definition. Rockville, Maryland: 2015. Available from: http://nhsc.hrsa.gov/ambassadors/hpsadefinition.html

28. Lo Sasso AT, Starkel RL, Warren MN, Guay AH, Vujicic M. Practice settings and dentists' job satisfaction. J Am Dent Assoc. 2015; 146(8):600-9. [PubMed: 26227645]

29. Vujicic M. The booming Medicaid market. J Am Dent Assoc. 2015; 146(2):136-8. [PubMed: 25637213]

30. American Dental Association Health Policy Institute. Report 1: Academic Programs, Enrollment and Graduates. Chicago, IL: 2015.

31. American Dental Education Association. ADEA Dean's Briefing Book, 2014-2015. Washington, DC: 2014. 


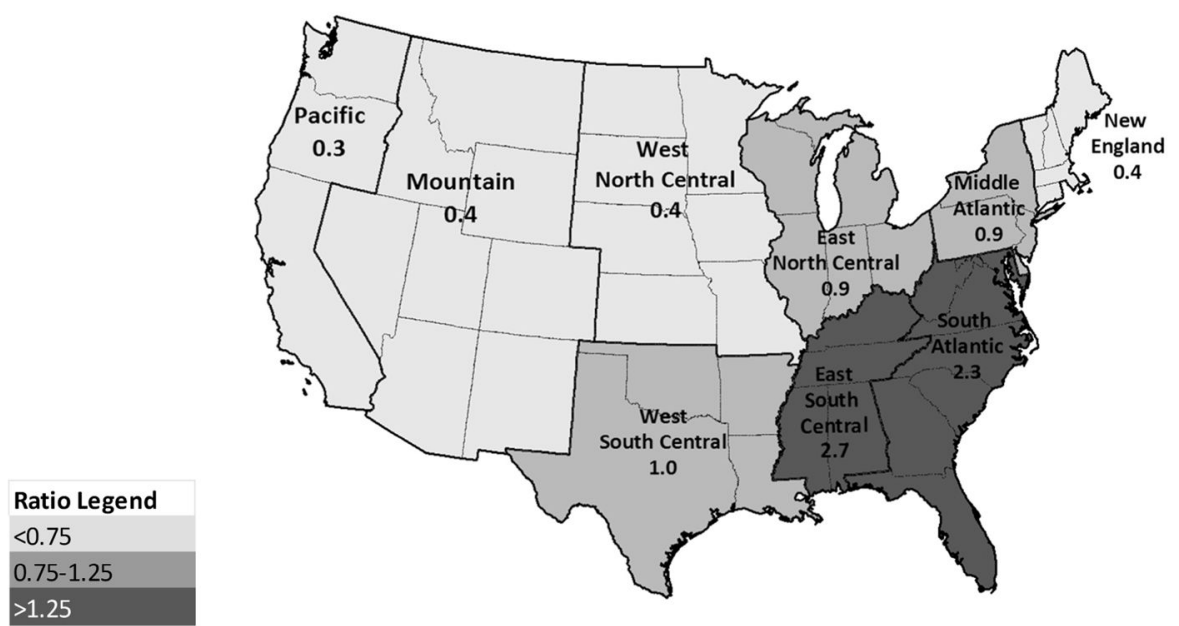

Figure 1. Ratio of Percent of Black Dentists to Percent of All Dentists in the U.S. by Census Division

*Pacific division includes Hawaii and Alaska. 


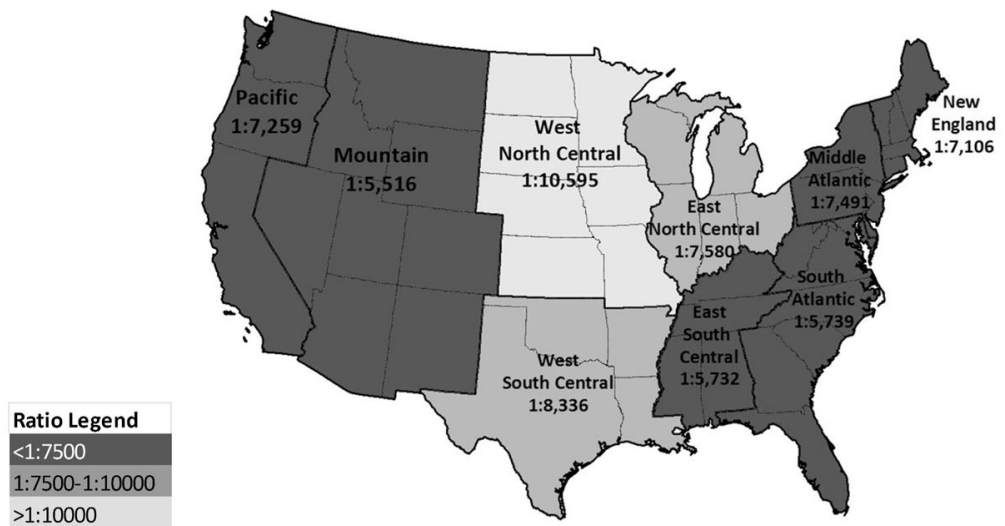

Figure 2.

Ratio of Black Dentists per Black Population by U.S. Census Division 


\section{Table 1}

Survey and Response of the Black Dentist Workforce in the U.S.

\begin{tabular}{|l|c|}
\hline & $\mathbf{N}^{*}$ \\
\hline Base Sample Surveyed from ADA Masterfile & 2,434 \\
\hline Deceased/Retired/Unlicensed & -37 \\
\hline Undeliverable/Could Not Locate & -172 \\
\hline Identified as Non-URM & -153 \\
\hline Working Outside of the U.S. & -6 \\
\hline Adjusted Number Surveyed & 2,066 \\
\hline Total Respondents (Unweighted) & 673 \\
\hline Adjusted Survey Response Rate $=$ Total Respondents/Adjusted Census & $\mathbf{3 2 . 6 \%}$ \\
\hline
\end{tabular}

Unweighted sample and respondents 


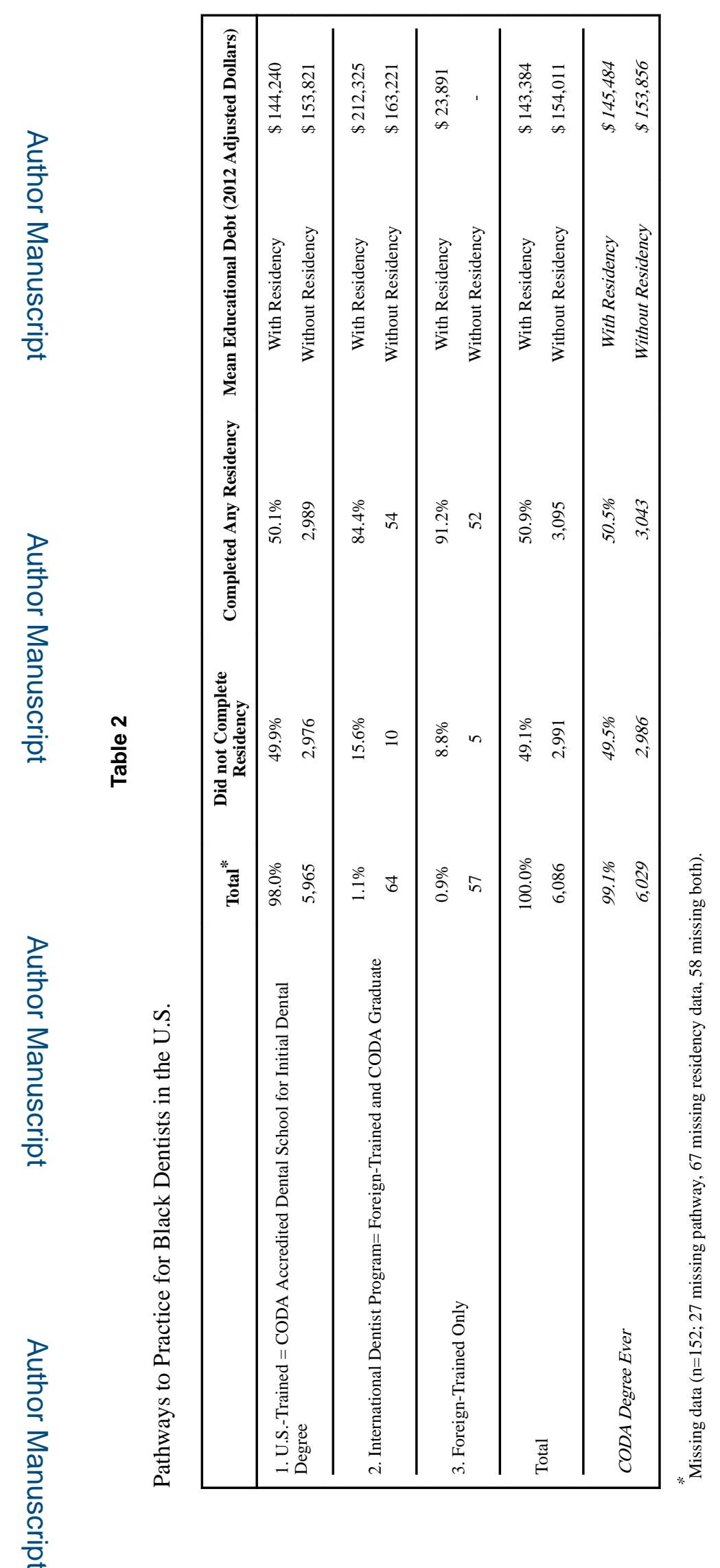

J Public Health Dent. Author manuscript; available in PMC 2017 June 19. 
Table 3

Type of Dental School Attended by Ever U.S.-Trained Black Dentists

\begin{tabular}{|l|c|c|c|}
\hline & Under 49 Years & 49+ Years & Total $^{*}$ \\
\hline Historically Black College or University (HBCU) & $35.1 \%(\mathrm{n}=910)$ & $51.0 \%(\mathrm{n}=1,760)$ & $44.2 \%(\mathrm{n}=2,670)$ \\
\hline Private University (Non-HBCU) & $14.7 \%(\mathrm{n}=380)$ & $14.1 \%(\mathrm{n}=488)$ & $14.4 \%(\mathrm{n}=868)$ \\
\hline Public University (Non-HCBU) & $50.2 \%(\mathrm{n}=1,299)$ & $34.9 \%(\mathrm{n}=1,204)$ & $41.4 \%(\mathrm{n}=2,503)$ \\
\hline Total & $100 \%(\mathrm{n}=2,589)$ & $100 \%(\mathrm{n}=3,452)$ & $100 \%(\mathrm{n}=6,041)$ \\
\hline
\end{tabular}

Missing data $(\mathrm{n}=72$, missing age data). 


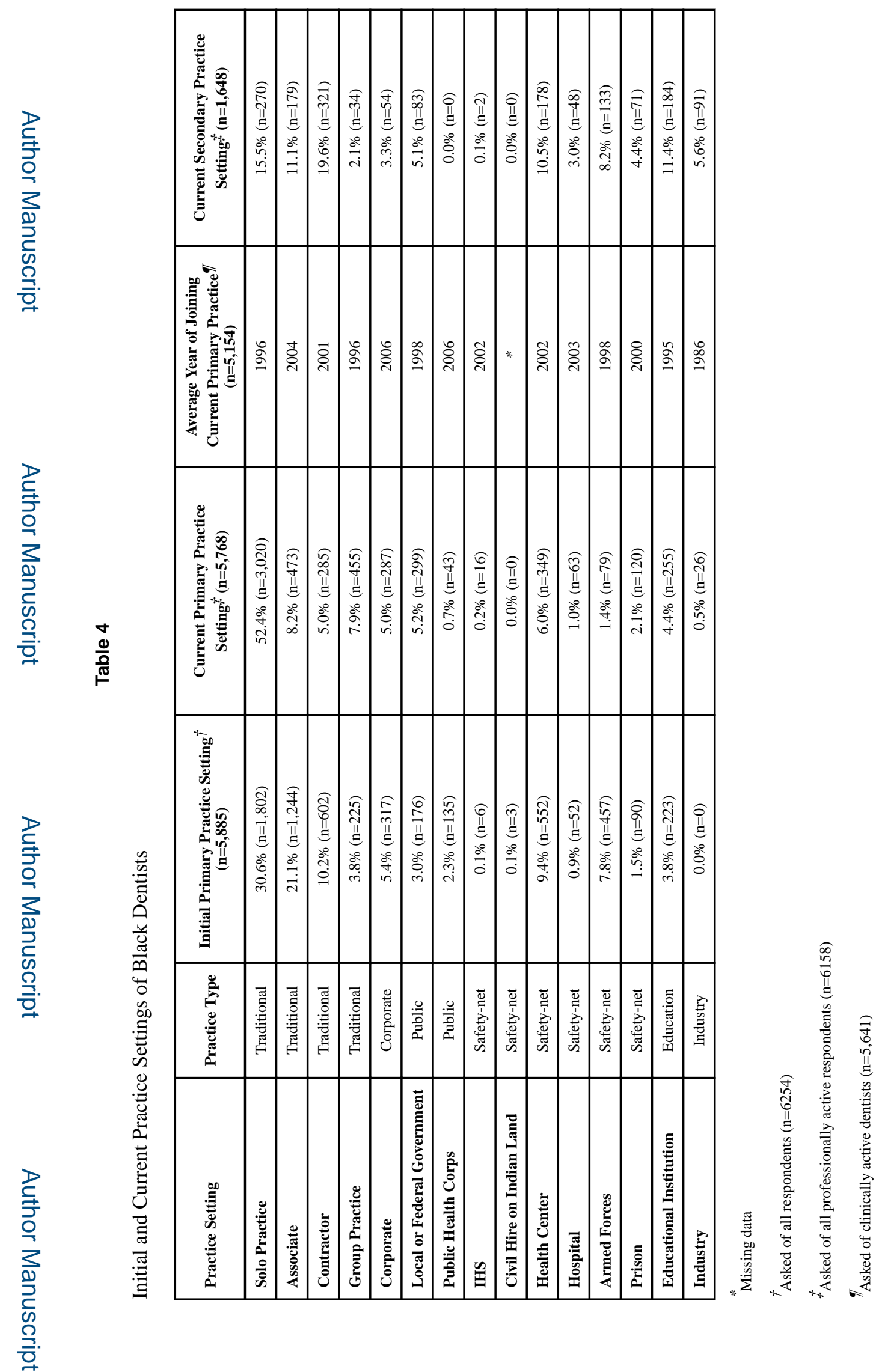

J Public Health Dent. Author manuscript; available in PMC 2017 June 19. 


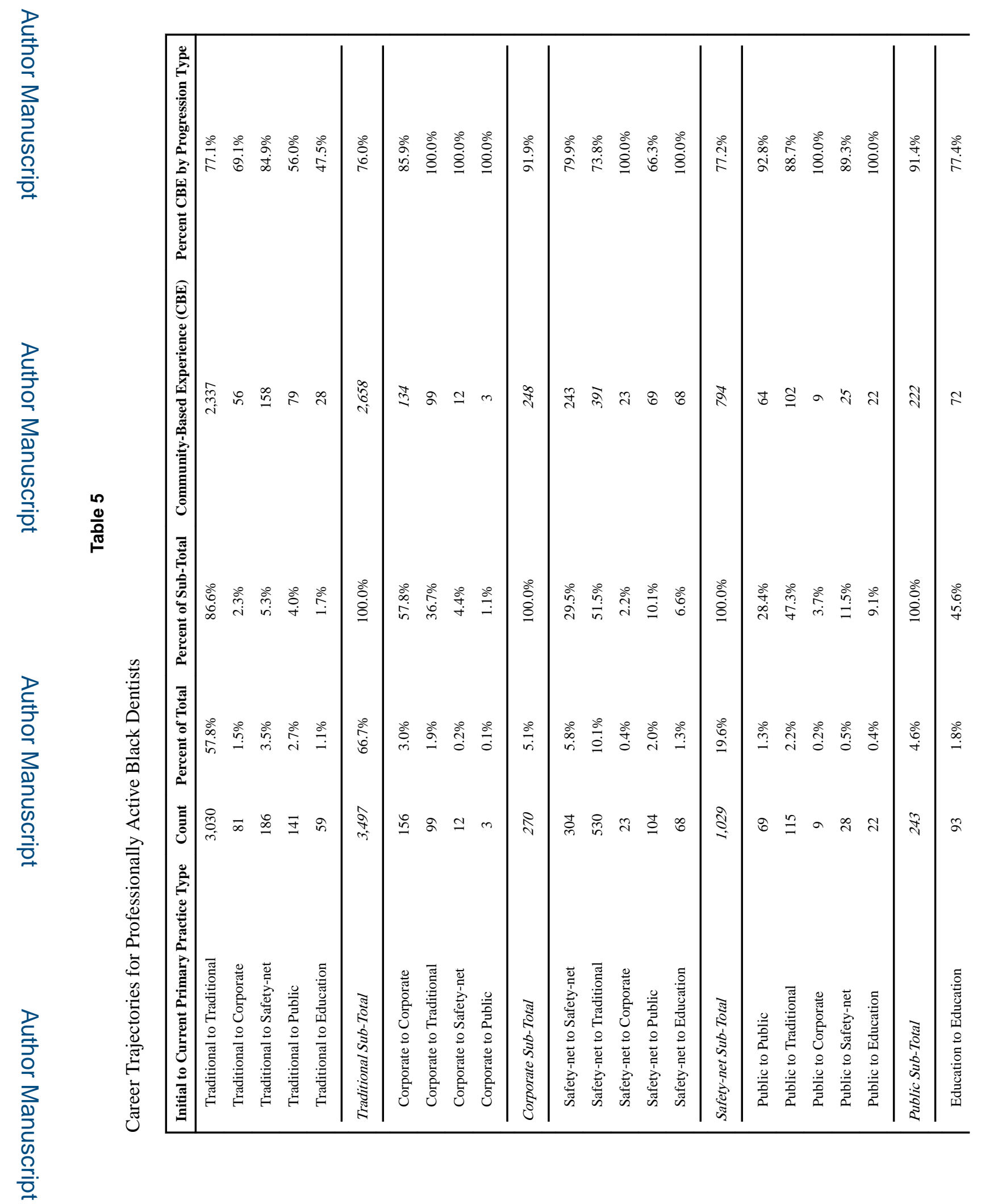

J Public Health Dent. Author manuscript; available in PMC 2017 June 19. 
Mertz et al.

Page 20

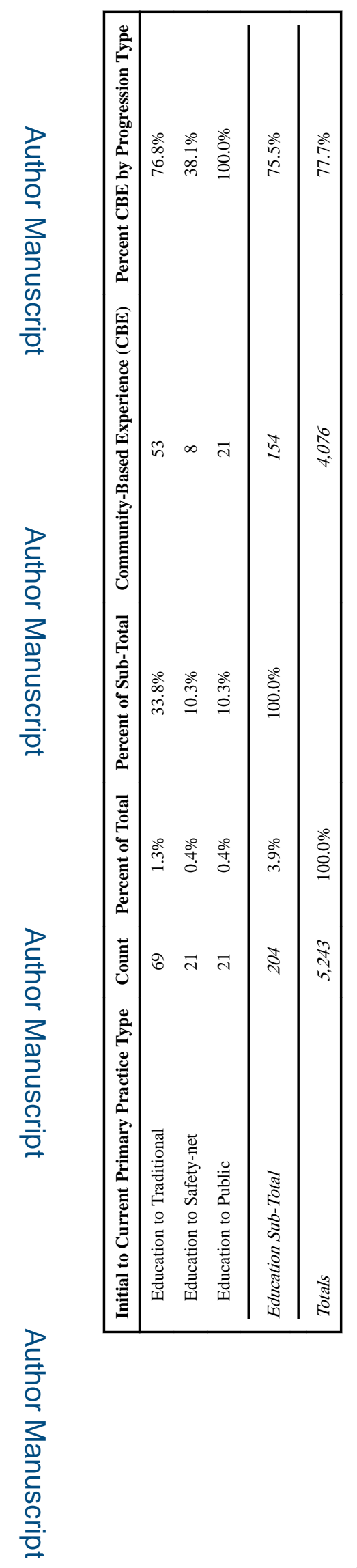

J Public Health Dent. Author manuscript; available in PMC 2017 June 19. 
Table 6

Medical Conditions of Black Dentists' Patient Population

\begin{tabular}{|l|c|c|}
\hline & $\begin{array}{c}\text { Percent of Black clinical dentists who } \\
\text { treat any patients with the } \\
\text { characteristics shown (n=5,039) }\end{array}$ & $\begin{array}{c}\text { Average percent of patient population } \\
\text { for Black dentists who treat any } \\
\text { patients with the characteristics shown }\end{array}$ \\
\hline Medically compromised & $94.5 \%$ & $21.6 \%$ \\
\hline Diabetes & $94.0 \%$ & $25.5 \%$ \\
\hline Physical disability & $89.9 \%$ & $7.6 \%$ \\
\hline Hypertension & $93.5 \%$ & $34.5 \%$ \\
\hline Developmental disability & $81.8 \%$ & $5.8 \%$ \\
\hline Pregnant & $84.1 \%$ & $6.4 \%$ \\
\hline Mental illness & $77.7 \%$ & $8.1 \%$ \\
\hline Low oral health literacy & $82.5 \%$ & $19.7 \%$ \\
\hline A severe behavior management problem & $62.9 \%$ & $7.0 \%$ \\
\hline Long term care resident or homebound & $51.2 \%$ & $6.4 \%$ \\
\hline HIV positive & $74.7 \%$ & $4.8 \%$ \\
\hline Prefer health information in a language other than & $70.1 \%$ & $13.9 \%$ \\
\hline English & & \\
\hline
\end{tabular}


Table 7

Demographics of Black Dentists' Patient Population

\begin{tabular}{|c|c|c|c|}
\hline Patient Age (years) $(n=4,978)$ & \multicolumn{3}{|c|}{ Average Estimated Percent of Patient Pool* } \\
\hline 0 to 1 & \multicolumn{3}{|c|}{$2.0 \%$} \\
\hline 2 to 5 & \multicolumn{3}{|c|}{$9.4 \%$} \\
\hline 6 to 17 & \multicolumn{3}{|c|}{$20.8 \%$} \\
\hline 19 to 64 & \multicolumn{3}{|c|}{$54.3 \%$} \\
\hline 65 to 85 & \multicolumn{3}{|c|}{$15.6 \%$} \\
\hline $85+$ & \multicolumn{3}{|c|}{$3.9 \%$} \\
\hline Gender and Sexual Orientation $(n=5,039)$ & $\begin{array}{l}\text { Percent of Black clinical } \\
\text { dentists who treat any } \\
\text { patients with the } \\
\text { characteristic }\end{array}$ & \multicolumn{2}{|c|}{$\begin{array}{c}\text { Average percent patient population among all Black } \\
\text { dentists }\end{array}$} \\
\hline Female & $97.5 \%$ & \multicolumn{2}{|c|}{$56.8 \%$} \\
\hline Lesbian, Gay, Bisexual, or Transgender & $69.6 \%$ & \multicolumn{2}{|c|}{$5.3 \%$} \\
\hline Race $(n=5,056)$ & $\begin{array}{c}\text { Average Estimated \% of } \\
\text { Patient Pool }\end{array}$ & Range (percent) & $\begin{array}{l}\text { Percent of U.S. } \\
\text { Population } t, \hbar\end{array}$ \\
\hline African American/Black & $44.9 \%$ & $0-100$ & $13.2 \%$ \\
\hline American Indian/Alaska Native & $3.8 \%$ & $0-100$ & $1.7 \% \pi$ \\
\hline Hispanic/Latino & $19.8 \%$ & $0-98$ & $16.2 \%$ \\
\hline Caucasian/White & $30.9 \%$ & $0-96$ & $74.1 \%$ \\
\hline Asian/Pacific Islander & $5.9 \%$ & $0-60$ & $5.5 \%$ \\
\hline Insurance Status $(n=4,943)$ & $\begin{array}{c}\text { Percent of Respondents who } \\
\text { treat any of the patient } \\
\text { population }\end{array}$ & $\begin{array}{l}\text { Average Percent of patient } \\
\text { population * }\end{array}$ & $\begin{array}{c}\text { Range of patient } \\
\text { population reported } \\
\text { (percent) }\end{array}$ \\
\hline Private insurance & $92.3 \%$ & $51.9 \%$ & $0-100$ \\
\hline Public insurance & $70.1 \%$ & $31.0 \%$ & $0-100$ \\
\hline Uninsured/Out-of-pocket & $93.3 \%$ & $20.1 \%$ & $0-100$ \\
\hline Other & $16.5 \%$ & $14.9 \%$ & $0-100$ \\
\hline
\end{tabular}

Will not add to $100 \%$ because averages are based on categories, not on the patient population as a whole.

${ }^{\dagger}$ Will not add to $100 \%$ because data does not include all census designations and collapses race and ethnicity; respondents identifying as Hispanic/ Latino may be included in any racial category.

tU.S. Census Bureau. American Community Survey, 2012 American Community Survey 3-Year Estimates, Tables S0201 and B03002. In: generated by C. Wides using American FactFinder, editor. 2015.

II Norris T, Vines P, Hoeffel E. The American Indian and Alaska Native Population: 2010. U.S. Census Bureau, 2012 January. Report No.: C2010BR-10. 
Table 8

Data Comparable from Unpublished 1992 Survey of Black Dentists and 2012 Survey

\begin{tabular}{|c|c|c|}
\hline & $1992(\text { Unweighted } n=748)^{*}$ & 2012 (Weighted $n=6,254) *$ \\
\hline Female & $19.4 \%$ & $45.4 \%$ \\
\hline Single & $10.7 \%$ & $16.0 \%$ \\
\hline Married & $74.7 \%$ & $68.0 \%$ \\
\hline Divorced & $10.5 \%$ & $16.0 \%$ \\
\hline No Dependents & $19.4 \%$ & $42.5 \%$ \\
\hline Hours Worked per Week & 31.2 & $41.1^{\dagger}$ \\
\hline Mean Age & 50.6 & 50.6 \\
\hline Mean Grad Year & 1973 (median) & 1990 \\
\hline No Post-Grad Residency & $53.3 \%$ & $49.2 \%$ \\
\hline General Practice & $81.9 \%$ & $76.3 \%+$ \\
\hline NDA Member & $62.1 \%$ & $35.3 \%$ \\
\hline ADA Member & $58.8 \%$ & $46.1 \%$ \\
\hline Patient Race by Quartiles of Patient Pool & 1992 & $2012^{f}$ \\
\hline \multicolumn{3}{|l|}{ Black } \\
\hline 0-25\% of All Patients Treated & $17.5 \%$ & $24.6 \%$ \\
\hline 26-50\% of All Patients Treated & $17.9 \%$ & $35.2 \%$ \\
\hline 51-75\% of All Patients Treated & $17.1 \%$ & $19.8 \%$ \\
\hline $75 \%+$ of All Patients Treated & $47.5 \%$ & $20.4 \%$ \\
\hline \multicolumn{3}{|l|}{ Asian } \\
\hline 0-25\% of All Patients Treated & $99.0 \%$ & $97.5 \%$ \\
\hline 26-50\% of All Patients Treated & $0.6 \%$ & $2.1 \%$ \\
\hline 51-75\% of All Patients Treated & $0.1 \%$ & $0.4 \%$ \\
\hline $75 \%+$ of All Patients Treated & $0.3 \%$ & $0.0 \%$ \\
\hline \multicolumn{3}{|l|}{ White } \\
\hline 0-25\% of All Patients Treated & $73.5 \%$ & $42.7 \%$ \\
\hline 26-50\% of All Patients Treated & $16.7 \%$ & $36.1 \%$ \\
\hline 51-75\% of All Patients Treated & $5.2 \%$ & $13.9 \%$ \\
\hline $75 \%+$ of All Patients Treated & $4.7 \%$ & $7.3 \%$ \\
\hline \multicolumn{3}{|l|}{ Hispanic } \\
\hline 0-25\% of All Patients Treated & $91.9 \%$ & $69.3 \%$ \\
\hline 26-50\% of All Patients Treated & $6.5 \%$ & $22.2 \%$ \\
\hline 51-75\% of All Patients Treated & $1.0 \%$ & $5.2 \%$ \\
\hline $75 \%+$ of All Patients Treated & $0.6 \%$ & $3.3 \%$ \\
\hline \multicolumn{3}{|l|}{ American Indian/Alaska Native } \\
\hline 0-25\% of All Patients Treated & $99.6 \%$ & $98.7 \%$ \\
\hline 26-50\% of All Patients Treated & $0.1 \%$ & $0.1 \%$ \\
\hline
\end{tabular}




\begin{tabular}{|c|c|c|}
\hline & 1992 (Unweighted $n=748$ ) & $2012($ Weighted $n=6,254) *$ \\
\hline 51-75\% of All Patients Treated & $0.0 \%$ & $0.3 \%$ \\
\hline $75 \%+$ of All Patients Treated & $0.3 \%$ & $0.8 \%$ \\
\hline Practice Characteristics & 1992 & $2012^{\dagger}$ \\
\hline Solo Practice & $65.5 \%$ & $52.4 \%$ \\
\hline Contractor & $3.8 \%$ & $5.0 \%$ \\
\hline Group Practice & $5.2 \%$ & $7.9 \%$ \\
\hline Associate & $7.5 \%$ & $8.2 \%$ \\
\hline Too Busy & $11.1 \%$ & $7.9 \%$ \\
\hline Not Busy Enough & $17.7 \%$ & $31.3 \% \%$ \\
\hline Armed Forces 1st & $18.7 \%$ & $7.8 \%$ \\
\hline
\end{tabular}

Subcategory respondents may not include entire N.

Professionally active Black dentists

tClinically active Black dentists 